\title{
The Biomechanics of Gender Difference and Whiplash Injury: Designing Safer Car Seats for Women
}

\author{
J. Mordaka, R. Gentle
}

Female car users are reported to have a higher incidence of soft tissue neck injuries in low speed rear-end collisions than males, and they apparently take longer to recover. This paper addresses the whiplash problem by developing a biomechanical FEM (Finite Element Method) model of the 50 th and the 5 th percentile female cervical spines, based on the earlier published male model created at the Nottingham Trent University. This model relies on grafting a detailed biomechanical model of the neck and head onto a standard HYBRID III dummy model. The overall philosophy of the investigation was to see if females responded essentially as scaled down males from the perspective of rear end collisions. It was found that detailed responses varied significantly with gender and it became clear that females cannot be modelled as scaled-down males, thus confirming the need for separate male and female biomechanical models and a revision of car test programmes and regulations which are currently based on the average male. Further investigation is needed to quantify the gender differences and then recommendations can be made for changes to the design of car seats and head restraints in order to reduce the risk of soft tissue injury to women.

Keywords: female, whiplash, rear impact, biomechanics, cervical spine, kinematics.

\section{Introduction}

\subsection{Whiplash}

The number of women drivers in the UK is growing faster than the number of men. According to the latest industry reports, women could soon outnumber men on the roads. There could be more than 20 million women drivers in the next 10 years if current trends continue [1,2]. In terms of safety, men are more likely than women to be killed in car crashes but female drivers have a higher risk of sustaining injury. This gender difference is apparent at slight injury level where the rate is $49 \%$ for females compared to $31 \%$ for males. Light injuries are most common during rear end accidents and they constitute $82 \%$ and $89 \%$ of all sustained injuries for male and female front occupants respectively. In comparison, in frontal impacts they are $66 \%$ for female and $65 \%$ for male percentage of all injuries [3]. Whilst most mild injuries are simply bruises, abrasions and lacerations, a very substantial proportion of spinal injuries are soft tissue neck injuries, so-called whiplash injuries [4]. Although classified as minor, their high incidence rate and long-term consequences lead to significant societal cost. The annual cost in the UK is estimated at $£ 2.5$ billion [5]. Symptoms include neck pain, stiffness, headaches, dizziness, blurred vision and numbness and may be associated with damage to the cervical muscles, ligaments, facet joints, nerve roots, vertebral arteries, or brain stem. However, despite numerous studies on human volunteers, cadavers, and animals, there is no consensus about which specific mechanisms are responsible for the majority of neck injuries to car occupants in rear-end impacts, although several have been proposed [6].

\subsection{Risk of whiplash injury for female car occupants}

A study of crash and insurance data shows a 1.5-2 times higher risk of neck soft tissue injury for female occupants than for men during low-speed impacts [7]. Females suffer more distortion and soft tissue bleeding (joint capsules, ligaments, muscles) [8] and sustain more $(+44 \%)$ long-term consequences $[9,10]$. The reasons for this are not clear to date. Some attempts have been made to attribute the gender difference in injury risk to anatomical, physiological, behavioural, and sociological parameters. Although many hypotheses have been proposed, the mechanism of cervical spine whiplash injury is not well understood and more research should be conducted.

\subsection{Sociological factors}

Women tend to driver smaller, lighter cars than men and this situation is disadvantageous since the car mass is a key factor in determining injury outcome. However, Koch et al [11] reported that the relative risk of injury in smaller struck cars was still higher for females than for males, even when the female was the driver. Otte et al [12] also suggested differences in sex-specific accident framework conditions and confirmed that women suffer neck injury in small cars more frequently than men. In the UK, medium cars are driven frequently by both sexes, however, $42 \%$ of female driver collisions are in small cars compared to $23 \%$ for males [2]. Furthermore, men have lower disability levels than women despite having on average less optimal head restraint positions [13]. It was suggested that females tend to sit farther foiward in their seats than males so their heads move farther before the headrest is reached [14]. Seating position also can affect spinal kinematics and increase the risk of injury. Matsumoto et al [15] showed that the percentage of kyphosis position is much higher for females than for males. Spine misalignment as a reason for soft tissue injury for women was pointed out by Ono et al [16], who showed that rotational angles of cervical vertebrae were larger at kyphosis for females, producing a higher probability of injury. 


\subsection{Psychological factor}

A completely different hypothesis was suggested by Spitzer et al [17] on the basis of clinical experience; women are likelier to report pain and disability cased by the injury. However, no data has been presented by insurance companies to confirm this.

\subsection{Physiological and anatomical factors}

Physiological and anatomical differences imply that the biomechanical tolerance of the female neck is lower than males and may explain differences in neck injury frequency. Temming et al [18] indicated that the risk of whiplash injury for both females and males increases with body height but females have higher risk of injury. Also injury risk is higher for females in each weight group [28], disproving the hypothesis of Kraft et al [19] that women are more vulnerable to soft neck injuries because they are generally lighter. Significant gender differences were noted for depths of the superior and inferior endplates of and height of the cervical vertebrae, with those for males being larger [20,21]. Differences in neck musculature between men and women are suggested as an important factor in neck injuries [22]. Cervical muscles can be sources of pain and influence neck motion, both passively and actively. Statistically, females have smaller neck circumferences, suggesting this may be the actual risk area. Furthermore, most muscles in women have a lower cross section than those in the men [23]. States [24] attributed the differences in injury risk to the ratio of head volume to cross sectional area of necks. For 50 th percentile males the ratio is $1: 135$ and for the comparable female it is $1: 151$, indicating females have narrower necks relative to head size. Male neck muscles are also stronger than female cervical muscles; the female strengths were $30-40 \%$ lower than their male counterparts [25] or according to others $20-25 \%$ lower [26]. According to Vasavada [27] males have 2-2.5 times greater moment-generating muscle capacities and only 1.1-1.3 greater mass and head inertia relative to women, suggesting female muscles work closer to maximum capacity. Muscle activation occurs $5 \%-15 \%$ earlier $[28,29]$ for females than males, which may be another source of higher risk for females. As females tend to have smaller and weaker supporting muscles in the cervical spine and also less body weight to collapse back support it can make them more vulnerable to neck injury [30]. Surprisingly, there is no comprehensive data describing differences between female and male ligaments in terms of geometry (cross area, length) and material properties (Young's modulus, load/deformation); this is a major shortcoming for any biomechanical analysis.

\subsection{Experimental tests}

During rear end impact sled experiments with volunteers there were observed differences in head-neck motions. Significant gender differences existed between the peak amplitude and time-to-peak amplitude. Females experience higher and earlier peak accelerations of head, torso, $\mathrm{C} 7-\mathrm{T} 1$ joint relative to earth, but this difference was not present for the head relative to the C7-T joint. Also women undergo smaller and earlier head extension than men [31]. Female volunteers demonstrated smaller rearward horizontal head translation
[32]. Generally females presented more rebound motion with larger thorax flexion angles than males.

\subsection{Safety tests}

In spite of the increasing number of female car users, and the higher incidence of soft neck injuries among women, the motor industry has been slow to recognise the new trend and some car manufacturers still do not take designing for female drivers seriously. Only a few attempts have been made to examine the biomechanical response of female cervical spines during car accidents. There is no 50th percentile female ATD (Anthropomorphic Test Dummy) or FEM dummy model in common use. The population of female drivers and occupants is represented by the 50th percentile male dummy in conjunction with the 5th percentile female dummy, even though it was shown by Carter [2] that $90 \%$ of female drivers in the UK are lighter and shorter than the 50th percentile male dummy. Table 1 indicates how poorly women are represented when designing safety systems.

Table 1: Basic measurements

\begin{tabular}{|l|c|c|c|}
\hline & $\begin{array}{c}\text { Mass } \\
{[\mathrm{kg}]} \\
{[33]}\end{array}$ & $\begin{array}{c}\text { Stature } \\
{[\mathrm{cm}]}\end{array}$ & $\begin{array}{c}\text { Head Mass } \\
{[\mathrm{kg}]} \\
{[34]}\end{array}$ \\
\hline 5th percentile Female & 45.00 & 151.44 & 2.93 \\
\hline 50th percentile Female & 66.70 & 162.00 & 3.64 \\
\hline 50th percentile Male & 79.75 & 175.50 & 4.44 \\
\hline $\begin{array}{l}\text { 5th percentile female } \\
\text { ATD }\end{array}$ & 50.00 & 152.00 & 3.70 \\
\hline $\begin{array}{l}\text { 5th percentile male } \\
\text { ATD }\end{array}$ & 71.20 & 165.00 & $?$ \\
\hline $\begin{array}{l}\text { 50th percentile male } \\
\text { ATD }\end{array}$ & 77.00 & 178.00 & 4.54 \\
\hline
\end{tabular}

\section{Models}

The models were developed in the LS-DYNA code. Because the cervical spine is a complex biomechanical system, the finite-element method seems well suited for parametric analytical study. FEM offers the advantage that it can handle complex geometric configurations and material, contact and geometric nonlinearities. This study deals with the relative head and neck motion in whiplash, focusing on differences between female and male models and aiming to explain the higher incidence of injury among women. The biomechanical responses from a 50 th percentile male dummy and a simple scaled-down 50 th percentile male dummy were compared against 50th and 5th percentile female models. The principal comparison is between a 50th percentile female model and a $93 \%$ scaled-down male during low speed rear-end impact. The typical load scenario in a rear-end collision is as follows:

1) The vehicle accelerates forward when struck

2) The torso is pushed forward by the seat

3) The spine starts straightening and the neck/torso joint rises 
4) The head lags behind the torso due to its inertia

5) The upper cervical spine undergoes flexion while the lower part undergoes extension, promoting an S-shape

6) The rise of the first thoracic vertebra, in (2) above, leads to a "ramping phenomenon" which causes cervical compression

7) The head rotates backward, producing a C-shape with extension of the entire cervical spine. Presence of a head restraint reduces the $\mathrm{C}$-shape.

8) The occupant rebounds out of the seat, leading to flexion of the cervical spine

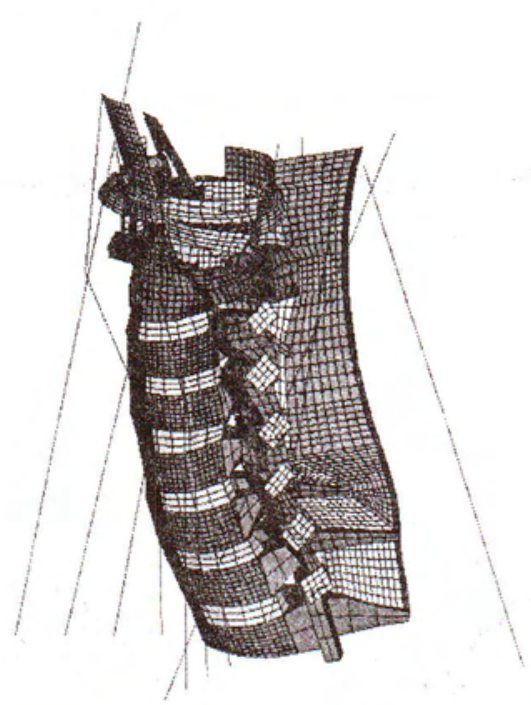

Fig. 1: FEM model of cervical spine

The basic 50th percentile male neck model was created by the Biomechanics Group at Nottingham Trent University [35] and consists of a biomechanical head-neck complex combined with the rigid Hybrid III dummy model in a simplified vehicle seat environment. Bony structures are modelled using shell elements with the geometry modified to achieve better interaction with soft tissue. All ligaments are represented, using a mixed structure of shell and non-linear springs elements, except for the Nuchal Ligament, which is modelled with shell elements only. The force/deformation load curves for discrete element are based on experimental results [36]. Shell element stiffness properties were calculated from $1 \%$ of the breaking force and corresponding deflection. Ligament geometry is based on available experimental data. Muscles are modelled by spring elements, as only passive action is represented, with material properties based on sternocleidomastoid muscles [37]. Intervertebral discs are represented using solid elements of Blatz-Ko rubber. The first approach in this study was structural scaling of the male model, defined as overall pure size reduction of the male spine without incorporating the characteristic female features. The model was scaled to $93 \%$, assuming that 50 th percentile females are $93 \%$ as tall as males.

The second model female was more sophisticated; it was again based on a $93 \%$ scaled male but allowed for a disproportionately larger female head mass (the 50th percentile female/male body mass ratio is $80 \%$ whereas the correspond- ing head mass ratio is $82 \%$ ) [34]. Strength properties of ligaments and muscle were modified assuming constant Young's modulus but reduced cross-sectional areas due to scaling. It was also taken into consideration that female vertebrae are more slender, Table 2.

Table 2: Anatomical parameters of vertebral height of the cervical spine

\begin{tabular}{|l|c|c|c|}
\hline & \multicolumn{3}{|c|}{ Vertebra height } \\
& Female & Male & $\begin{array}{c}\text { Female-Male } \\
\text { ratio }\end{array}$ \\
\cline { 2 - 4 } & Forior height divided by depth) \\
\hline $\begin{array}{l}\text { The third cervical } \\
\text { vertebra (C3) }\end{array}$ & 0.935 & 0.911 & 1.0263 \\
\hline $\begin{array}{l}\text { The forth cervical } \\
\text { vertebra (C4) }\end{array}$ & 0.883 & 0.844 & 1.0462 \\
\hline $\begin{array}{l}\text { The fifth cervical } \\
\text { vertebra (C5) }\end{array}$ & 0.845 & 0.812 & 1.0406 \\
\hline $\begin{array}{l}\text { The sixth cervical } \\
\text { vertebra (C6) }\end{array}$ & 0.834 & 0.846 & 0.9858 \\
\hline $\begin{array}{l}\text { The seventh cervi- } \\
\text { cal vertebra (C7) }\end{array}$ & 0.909 & 0.923 & 0.9848 \\
\hline
\end{tabular}

The impact loading data for the present study was based on sled experiments with a standard car seat mounted on a trolley, accelerated to simulate rear-end impact at $\Delta \mathrm{V}=9.5 \mathrm{~km} / \mathrm{h}[31]$.

\section{Validation}

Experiments made by Kronenberg et al [31], were used to evaluate the models. Linear acceleration of the head and the first thoracic vertebra (T1) were obtained. Head angle and trajectories were filmed. Data were taken from a subject whose measurements matched closely the mass and seating height of 50th percentile UK females and males. The marked increase in head $\mathrm{x}$-acceleration and differences in head-neck kinematics observed for females compared to males in the experiments was confirmed by the computational models. The peak head acceleration is higher and earlier for females than males. However, the acceleration is 10 times higher than experiments because in the FEM model an unrealistic rigid seat model is used.

Reasonably good agreement was found for head rotation. In sled tests carried out by Siegmund et al [32] the females experienced smaller and earlier peak head extension than males. The FEM models confirmed this even though peak values were always higher than the experiment. In this study only a passive muscle response is modelled. This seems to suggest that muscle contraction plays a significant role in cervical spine kinematics, although the muscle onset is developed 80-90 ms after impact [38] and full muscle forces are not developed until 60-70 ms later [39]. It also may explain later peak head extension for women, particularly that they activated their muscles earlier. 


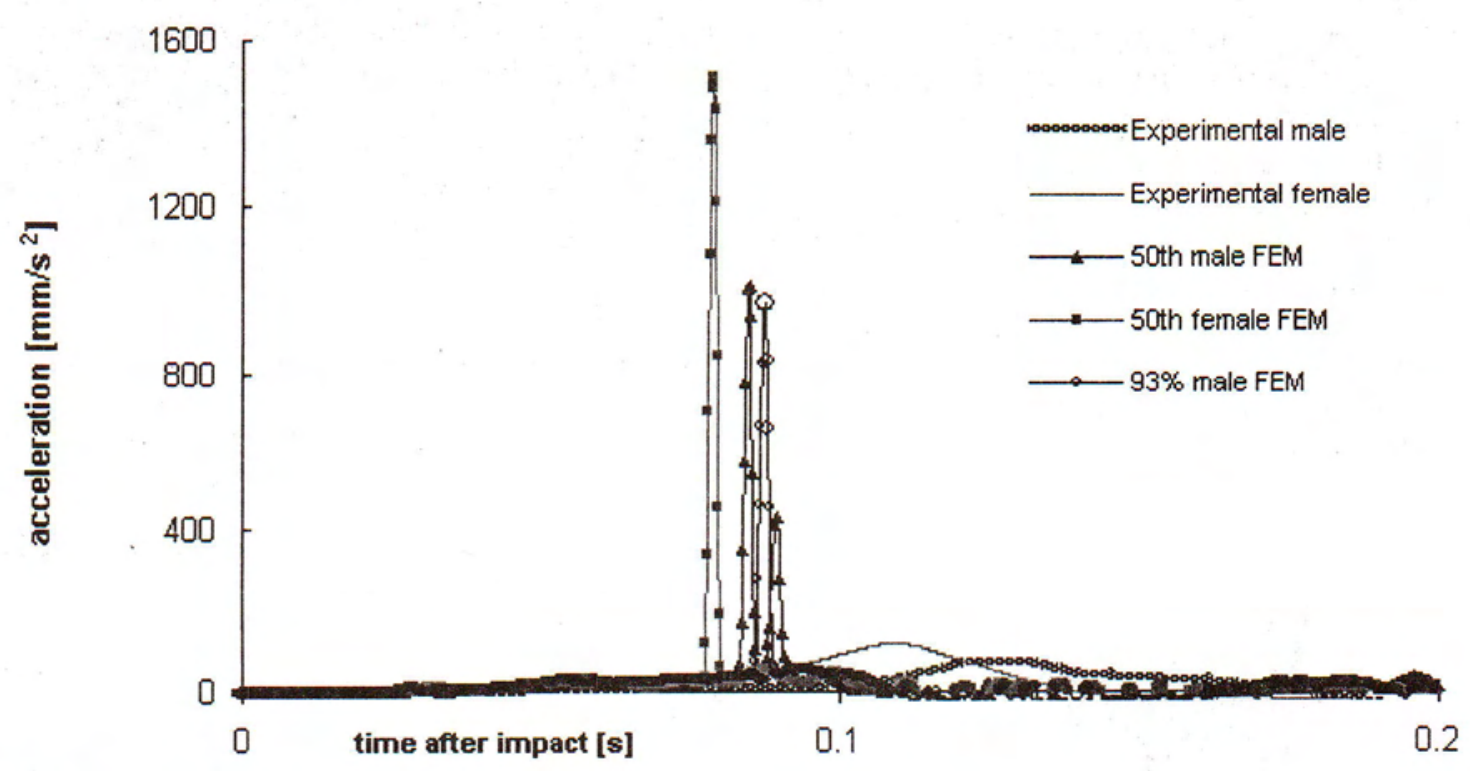

Fig. 2: Head horizontal acceleration

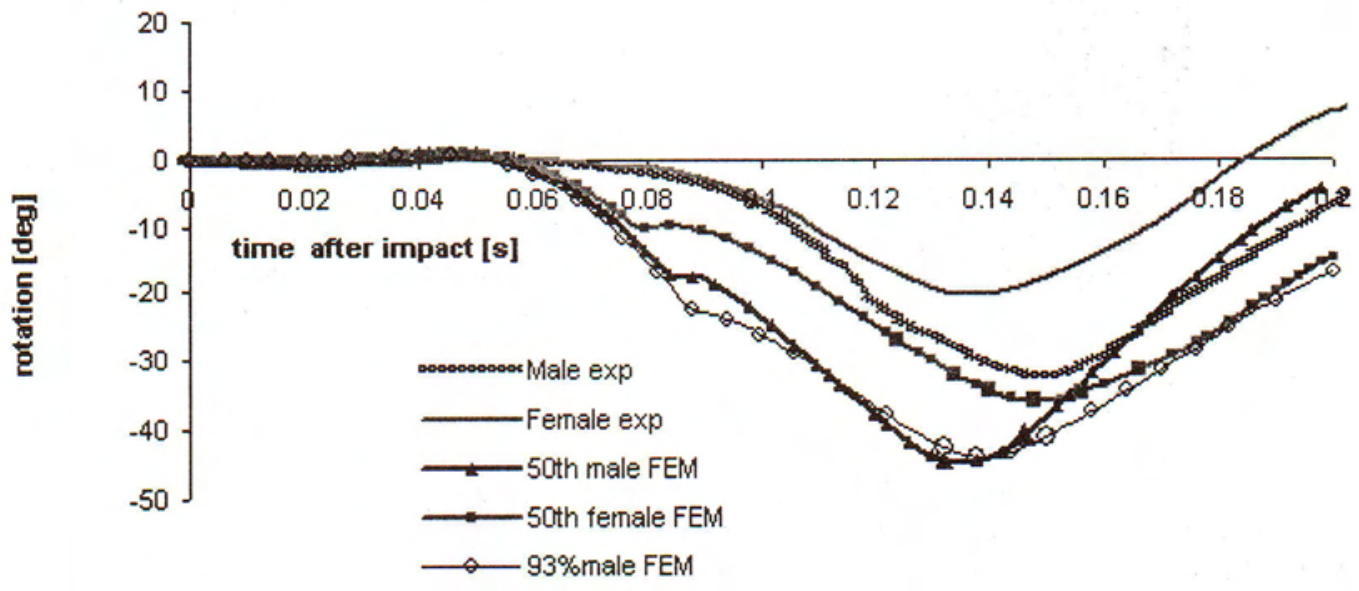

Fig. 3: Head rotation relative to earth

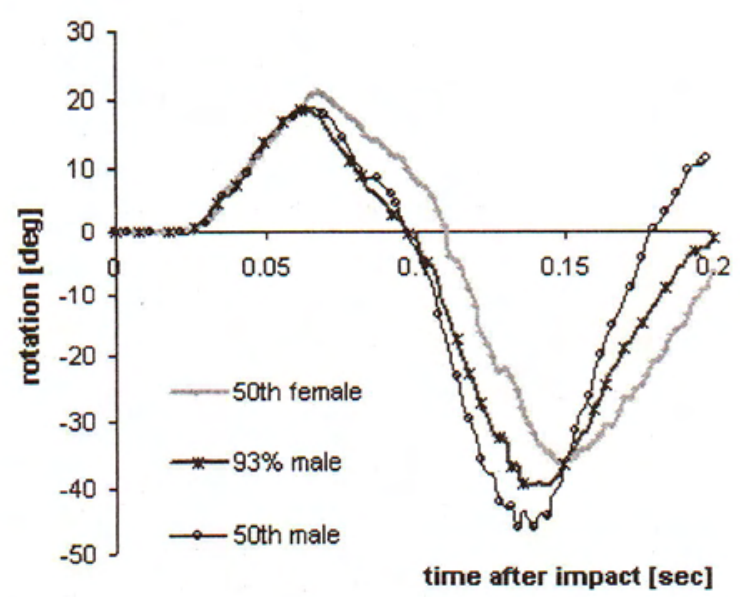

Fig. 4: Head rotation relative to $\mathrm{C} 3$

\section{Results}

The biomechanical model of the female cervical spine is intended to solve the mystery of higher risk of injury for females. The simplified scaled down male model shows similarity in several parameters to male models rather than female. The relative rotation between the head and C3 produces hyperflexion which is considered a potential neck injury mechanism. The flexion is higher for the female model, both the 50th male and $93 \%$ scaled down male. The curve for the $93 \%$ scaled down model in the first second after impact shows the same shape as the 50th percentile male (Fig. 4). There was higher axial force on tectorial membrane (TM) and vertical ligament (VC) in the female model than both male models (Figs. 5, 6). There are a few hypotheses that assume that injuries of upper level ligaments predominate in whiplash injury due to hypertranslation or combined shear and compression [40, 41, 42]. 


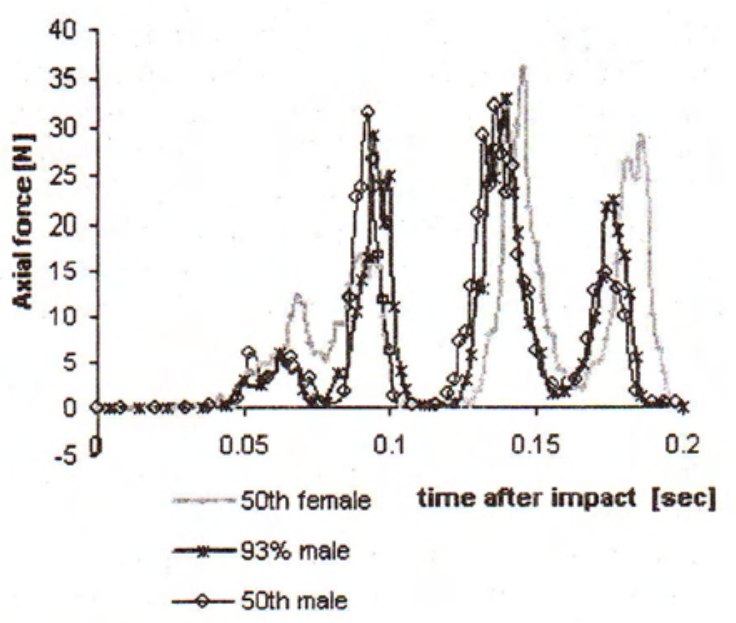

Fig. 5: Axial forces TM

Higher axial forces on ligaments: alar (AL), apical (AP) and AAOM (anterior antlanto-occipital membrane) and CP (joint capsules) were observed during rebound motion. Because females experience more rebound motion this might be a reason for the higher risk of injury, as Krafft et al [19] suggested that injuries occur during the rebound sequence when posterior tissues are stressed and the anterior tissues in the neck are compressed (Figs. 6, 7).

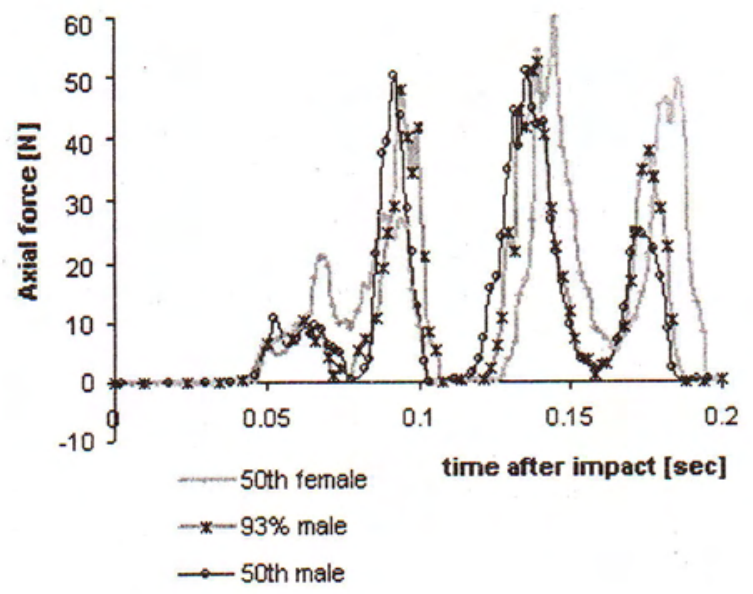

Fig. 6: Axial forces on VC ligament

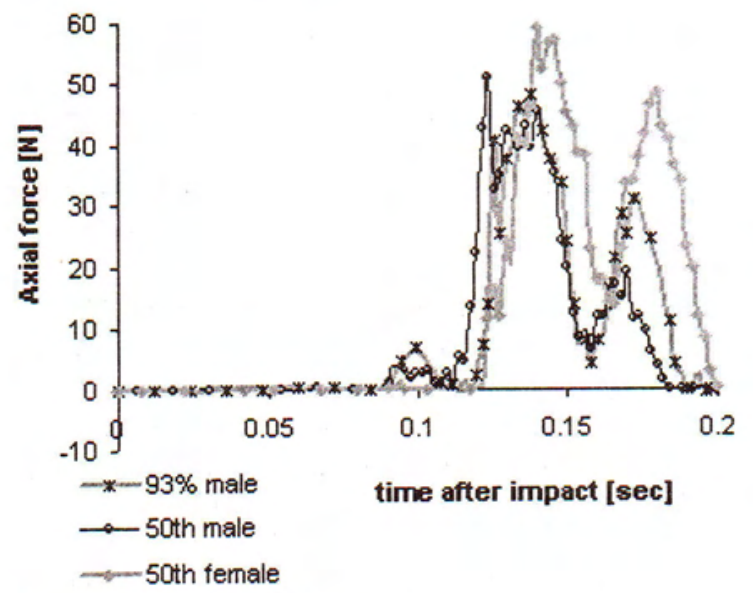

Fig. 7: Axial forces AAOM ligament
Panjabi and associates [43] propose that the lower cervical spine is injured in hyperextension when the spine forms an S-shape curve before the neck is fully extended. This intervertebral rotation beyond physiological limits implies the stretching of the anterior and compression of the posterior elements of the lower cervical spine. They observed that intervertebral rotation at lower segments exceeded maximum physiological extension. The anterior injury at C5-C6 level was observed. In our model it was noticed during the first phase of loading that the female model experienced higher C5 rotation relative to $\mathrm{C} 6$ (Fig. 8) than the male model and also higher axial forces at anterior longitudinal ligament (ALL), Fig. 9. This may be a potential explanation for the higher risk of whiplash injury for women.

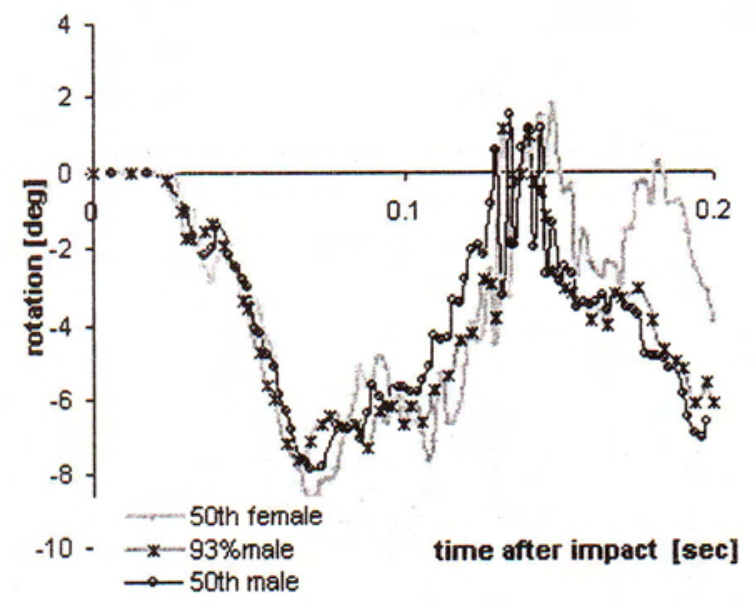

Fig. 8: C5-C6 intervertebral rotation

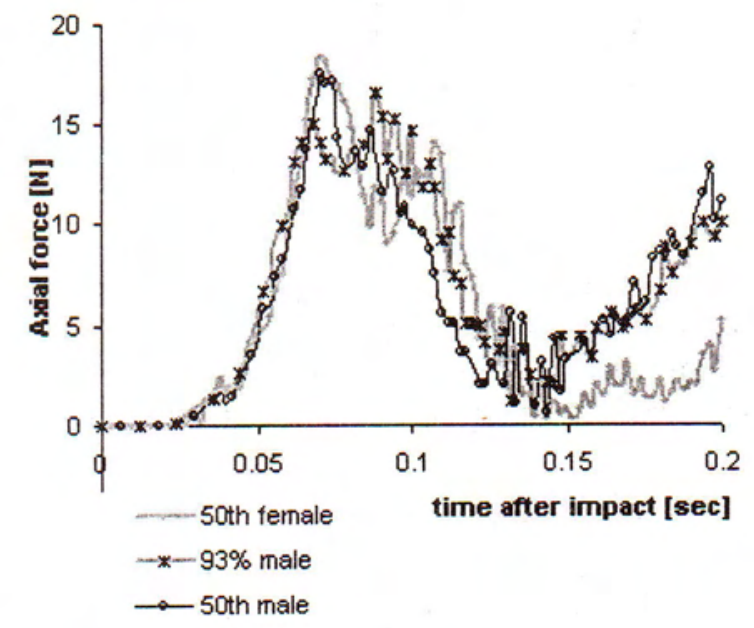

Fig. 9: Axial forces ALL ligament at C5-C6 level

Yoganandan et al [44] suggested that during whiplash loading the lower facet joint undergoes dissimilar compression combined with anterior-posterior sliding of the facet joint, resulting in a pinching mechanism. From Fig. 10 and 11 it is observed that during the first phase the C5 vertebra slides backwards. At the same time vertical translation is observed. At peak extension C5 is shifted downward, which may produce compression in the posterior part of the vertebra and stretch the anterior tissue. Moreover, these relative vertical 
and horizontal motions are higher for female models, suggesting it might be related to a higher injury occurrence.

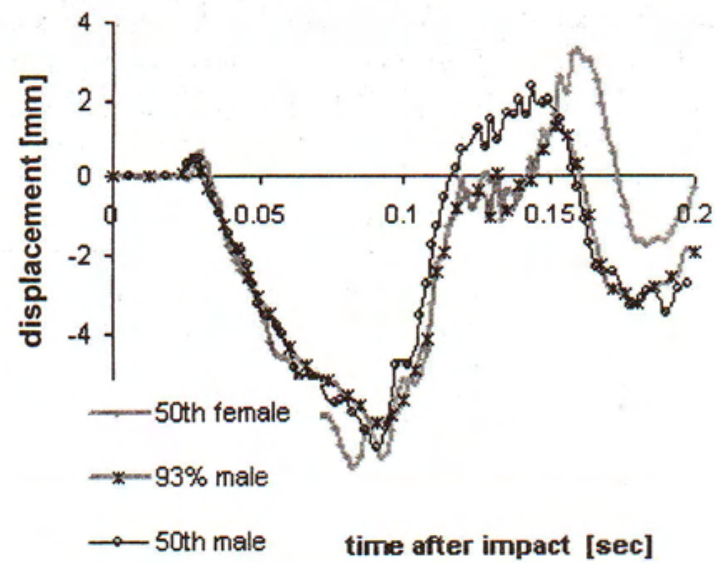

Fig. 10: C5 horizontal displacement relative to C6

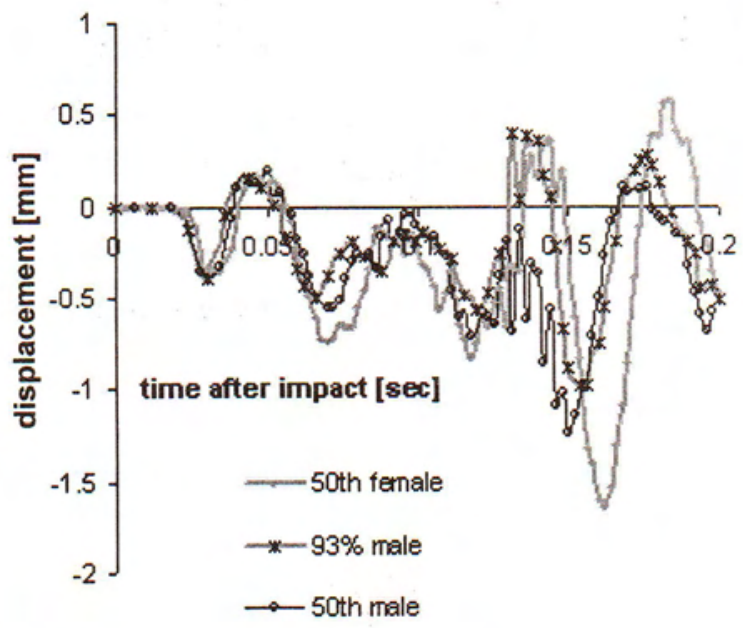

Fig. 11: C5 vertical displacement relative to C6

It should be noted that for female models there is higher downward translation during rebound motion, followed by an upward shift. The models show significant gender difference in vertebral motions which should not be neglected.

\section{Conclusion}

Female neck biomechanics is a complex issue, exacerbated by a distinct lack of biomechanical data. The exact mechanism of so-called whiplash injury is not established and there are several hypotheses about the source of pain. In spite of the observed higher risk of injury for female car occupants most research has involved male subjects or gender differences were not specified. The 50 th and 5 th percentile male dummies, both ADT and FEM models, do not represent the average female. The $93 \%$ scaled down male model is not adequate to simulate female responses even though the scaling constitutes a good height and mass match. The 50th percentile female model was in general agreement with test results considering the lack of data about female neck biomechanical properties. This preliminary female model exhibited a satisfactory correlation with experimental results and the gender differences in kinematics prove the need for a 50 th percentile female model. The observed difference in head rotation relative to $\mathrm{C} 3$ and $\mathrm{C} 5$ - $\mathrm{C} 6$ relative motion could be potential causes of the higher neck injury in females, and needs further consideration. It was shown that there were higher axial forces in cervical ligaments for female than for male models, supporting the theory that females are more vulnerable to whiplash injury.

Further model developments are needed in the following areas:

1. Enhancement of muscle response by modeling active response.

2. Remodeling vertebra geometry to incorporate more detailed gender differences in height and cross section area.

3. Better car seat representation.

4. Cervical spine alignment evaluation.

More research should be performed to understand soft neck injuries, mechanisms and thresholds. Standardised calculation of risk of injury would enable comparison. Further study should evaluate gender differences in biomechanical head and neck response during whiplash.

\section{References}

[1] Women in the fast lane, http://news.bbc.co.uk/1/hi/uk/79670.stm.

[2] Carter, M., Welsh, R.: In-car Safety and Personal Security Needs of Female Drivers and Passengers. Proc. of ImechE Conference, VS 2002', London, May 2002, p. 267-281.

[3] Lenard, J., Welsh, R.: A Comparison of Injury Risk and Pattern of Injury between Male and Female Occupants of Modern European Passenger Cars. Proc. of the IRCOBI Conference on the Biomechanics of Injury, Isle of Man (UK), 2001.

[4] Welsh, R., Lenard, J.: Male and Female Car Drivers-Differences in Collision and Injury Risks. Proc. of 45th Conference of the Association for the Advancement of Automotive Medicine, Texas (USA), 45, September 2001, p. 73-91.

[5] Galasko, C. S.: Whiplash Associated Disorders: Cost to Society. International Symposium Whiplash'96, Current Concepts in the Prevention, Diagnosis, and Treatment of the Cervical Whiplash Syndrome, Brussels (Belgium), 16 November, 1996, p. 55.

[6] Szabo, T. J.: Influence of Seat Properties on Occupant Kinematics and Injury Potential in Low-Speed Rear Impact. In: "Frontiers in Whiplash Trauma" (Editors: N. Yoganandan and F. A. Pintar). Amsterdam: IOS Press, 2000, p. 348-371.

[7] Morris, A. P.,Thomas, P.: Neck Injuries in the UK Co-Operative Crash Injury Study. SAE Technical Paper 962433, 1996, p. 317-329.

[8] Hell, W., Shick, S., Langwieder, K.: Epidemiology of Cervical Spine Injuries in Rear-End Collisions and Influence of Different Anthropometric Parameters in Human Volunteer Tests. In: "Frontiers in Whiplash Trauma" (Editors: N. Yoganandan and F. A. Pintar). Amsterdam: IOS Press, 2000, p. 146-163. 
[9] Krafft, M.: A Comparison of Short and Long Term Consequences of AIS 1 Neck Injuries in Rear Impacts. Proc. of the International IRCOBI Conference on the Biomechanics of Impacts, Göteborg (Sweden), September 16-18, 1998, p. 235-248.

[10] Hohl, M.: Soft-Tissue Injuries of Neck in Automobile Accidents. J. Bone and Joint Surgery, 56-A (8), 1974, p. 1675-1682.

[11] Koch, M. et al: Soft Tissue Injury of the Cervical Spine in Rear End and Frontal Collision. Proc. of the International IRCOBI Conference on the Biomechanics of Impact, Brunnen (Switzerland), September 13-15, 1995, p. 273-283.

[12] Otte, D., Pohlemann, T., Blauth, M.: Significance of Soft Tissue Neck Injuries AIS1 in the Accident Scene and Deformation Characteristics of Cars with Delta-v up to $10 \mathrm{~km} / \mathrm{h}$. Proc. of the International IRCOBI Conference on the Biomechanics of Impacts, Hanover (Germany), September 24-26, 1997, p. 265-283.

[13] Minton, R. et al: Causative Factors in Whiplash Injury: Implications for Current Seat and Head Restraint design. Proc. of the International IRCOBI Conference on the Biomechanics of Impacts, Hanover (Germany), September 24-26, 1997, p. 207-222.

[14] IIHS: Whiplash Injuries. Status Report 30(8), Arlington (USA): Insurance Institute for Highway Safety, 1995.

[15] Matsumoto, T. et al: Relationship Between Cervical Curvature and Discs Degeneration in Asymptomatic Subject. Journal of Eastern Japan Association of Orthopaedics and Traumatology in Japanese Journal, 9, 1977, p. 1-4.

[16] Ono, K. et al: Cervical Injury Mechanism Based on the Analysis of Human Cervical Vertebral Motions and Head-Neck-Torso Kinematics During Low Speed Rear Impacts. (973340), Proc. $41^{\text {st }}$ Stapp Car Crash Conference, Lake Buena Vista (USA), 1997, p. 339-356.

[17] Spitzer, W. O. et al: Scientific Monograph of the Quebec Task Force on Whiplash-Associated Disorders: Redefining Whiplash and its Management. Spine, 20 (8S), 1995, p. 1S-73S.

[18] Temming, J., Zobel, R.: Neck Distortion Injuries in Road Traffic Crashes (Analyses of the Volkswagen Database). In: "Frontiers in Whiplash Trauma" (Editors: N. Yoganandan and F. A. Pintar). Amsterdam: IOS Press, 2000, p. 119-133.

[19] Krafft, M. et al: Whiplash Associated Disorders- Factors Influencing the Incidence in Rear-ed Collision. Proc. $15^{\text {th }}$ ESV-Conference, 1996, p. 1426-1432.

[20] Ebraheim, N. A. et al: The Vertebral Body Depth of the Cervical Spine and its Relation to Anterior Plate-Screw Fixation. Spine, Vol. 23, No. 21, 1998, p. 2299-2302.

[21] Frobin, W. et al: Vertebral Height, Disc Height, Posteroanterior Displacement and Dens-Atlas Gap in the Cervical Spine: Precision Measurement Protocol and Normal Data. Clinical Biomechanics, Vol. 17, No. 6, 2002, p. 423-431.

[22] Cerelli, E.: Female Drivers in Fatal Crashes, Recent Trends. Technical Report NHTSA DOT HS 808 106, National Technical Information Service, 1992.

[23] Kamibayash, L. et al: Morphometry of Human Neck Muscles. Spine, Vol. 23, No. 12, 1998, p. 1314-1323.
[24] States, J. D. et al: Injury Frequency and Head Restraint Effectiveness in Rear-End Impact Accidents. In: Proc. $16^{\text {th }}$ Stapp Car Crash Conference, New York (US), 1972, p. 228-245.

[25] Kumar, S., Narayan, Y., Amell, T.: Cervical Strength of Young Adults in Sagittal, Coronal and Intermediate Planes. Clinical Biomechanics, Vol. 16, 2001, p. 380-388.

[26] Jordon, A., Mehlsen, J., Bulow, P. M.: Maximal Isometric Strength of Cervical Musculature in 100 Healthy Volunteers. Spine, Vol. 24, 1999, p. 1343-1348.

[27] Vasavada, A. N., Li, S. Delp, S. L.: Three-Dimensional Isometric Strength of Neck Muscles in Humans. Spine, Vol. 26, No. 17, 2001, p. 1904-1909.

[28] Brault, J. R., Siegmund, G. P., Wheeler J. B.: Cervical Muscle Response During Whiplash: Evidence of Lengthening Muscle Contraction. Clinical Biomechanics, Vol. 15, 2000, p. $426-435$.

[29] Szabo, T. J, Welcher, J. B.: Human Subject Kinematics and Electromyographic Activity During Low Speed Rear Impacts. Proc. of the $40^{\text {th }}$ Stapp Car Crash Conference (962432), Albuquerque (USA), 1996, p. 339-356.

[30] Otremski, I. et al: Soft Tissue Cervical Spine Injuries in Motor Vehicle Accidents. Injury, Vol. 20, 1989, p. 349-351.

[31] Kroonenberg, A. van den, Philippens, M., Cappon, H., Wismans, J., Hell, W., Langwieder, K.: Human Head-Neck Response During Low-Speed Rear End Impacts. Stapp Car Crash Conference Proceedings, 1998, SAE 983158.

[32] Siegmund, G. P. et al: Head/neck Kinematic Response of Human Subjects in Low-Speed Rear-End Collisions (973341). Proc. $41^{\text {st }}$ Stapp Car Crash Conference, Lake Buena Vista (USA), November 1997, p. 357-385.

[33] People Size Software, 1998, Open Ergonomics Ltd., Loughborough Technology Center, UK, 1998.

[34] Kleiven, S., Holst, H.: Consequences of Head Size Following Trauma to the Human Head. Journal of Biomechanics, Vol. 35, 2002, p. 153-160.

[35] Golinski, W.: Three-Dimensional Dynamic Modelling of Human Cervical Spine in Whiplash Situations. PhD thesis, Nottingham Trent University, Nottingham 2000.

[36] Myklebust, J. B. et al: Tensile Strength of Spinal Ligaments. Spine, Vol. 13, 1988, p. 526-531.

[37] Yamadda, H.: Strength of Biological Materials. Baltimore: The Williams \& Wilkins Comp, 1970, p. 93-95.

[38] Brault, J. R., Siegmund, G. P., Wheeler J. B.: Cervical Muscle Response During Whiplash: Evidence of Lengthening Muscle Contraction. Clinical Biomechanics, Vol. 15, 2000, p. $426-435$.

[39] Szabo, T. J., Welcher, J. B.: Human Subject Kinematics and Electromyographic Activity During Low Speed Rear Impacts. Proc. of the $40^{\text {th }}$ Stapp Car Crash Conference (962432), Albuquerque (USA), 1996, p. 339-356.

[40] Yang, K. H. et al: On the Role of Cervical Facet Joints in Rear End Impact Neck Injury Mechanisms. SAE Technical Paper 970497, 1997, p. 127-129.

[41] Penning, L.: Acceleration Injury of the Cervical Spine by Hypertranslation of the Head: Part 1. Effect of Normal Translation of the Head on the Cervical Spine Motion: a Radiological Study. Eur Spine J., Vol. 1, 1992, p. 7-12. 
[42] Penning, L.: Acceleration Injury of the Cervical Spine by Hypertranslation of the Head: Part 2. Effect of Hypertranslation of the Head on the Cervical Spine Motion: Discussion of Literature Data. Eur Spine J., Vol. 1, 1992, p. 13-19.

[43] Panjabi, M. M. et al: Mechanism of Whiplash Injury. Clinical Biomechanics, Vol. 13, 1998, p. 239-249.

[44] Yoganandan, N., Pintar, F. A., Cusick, J. F.: Biomechanical Analyses of Whiplash Injuries Using Experimental Model. Accident Anal \& Prev, Vol. 34, No. 5, 2001, p. 101-109.

Justyna Mordaka

e-mail: justyna.mordaka@ntu.ac.uk

Prof. Richard C. Gentle

School of Engineering,

The Nottingham Trent University,

Burton Street, Nottingham,

NG1 4BU, United Kingdom 